\title{
Vicarious wounds
}

$\mathrm{M}$ aybe no one had thought of it," he said. "Or maybe they had, but didn't want to say $i t$. Whatever the reason, no one warned me about the pain medicine inflicts." he reflected.

It had crept up on him over time, this sadness. The product of his compassion; this despondency oppressed his every day.

"I thought I'd save lives and help people; that I'd feel great about my work," he lamented.

Instead, his patients' sadness, their despair, their suffering and their remorse lived within him. Concentrated in his soul. Poisoned his spirit.

Empathy can be a double-edged sword.

"Talk to someone, they say ..." he snickered with irony.

"Useless solution," he answered himself with disdain.

"How can anyone understand what Ifeel?" he cried.

"Can you really describe to anyone the silence in the room, as a woman, exhausted, pushes to deliver what she knows is a dead baby? Or the sorrow in her eyes when she sees his macerated skin? How do I convey the apprehension I felt when I closed the door after I wheeled a toddler into a fridge for the night? Will anyone stay awake like I did, thinking of his mother imagining her baby; alone, cold and in the dark, without his blankie? How do you describe your shock, at the unnatural coldness of a body at autopsy? Can anyone even imagine trying to work, distracted by visions of your own child, cut from neck to pubis under the glare of police flashes? Can you imagine my unease, knowing that beneath that pretty dress, her organs are unceremoniously stuffed inside a garbage bag and hidden in her chest; sewn with cotton string? Can someone really feel the gruesome shock I felt when I took off the stiff collar on that

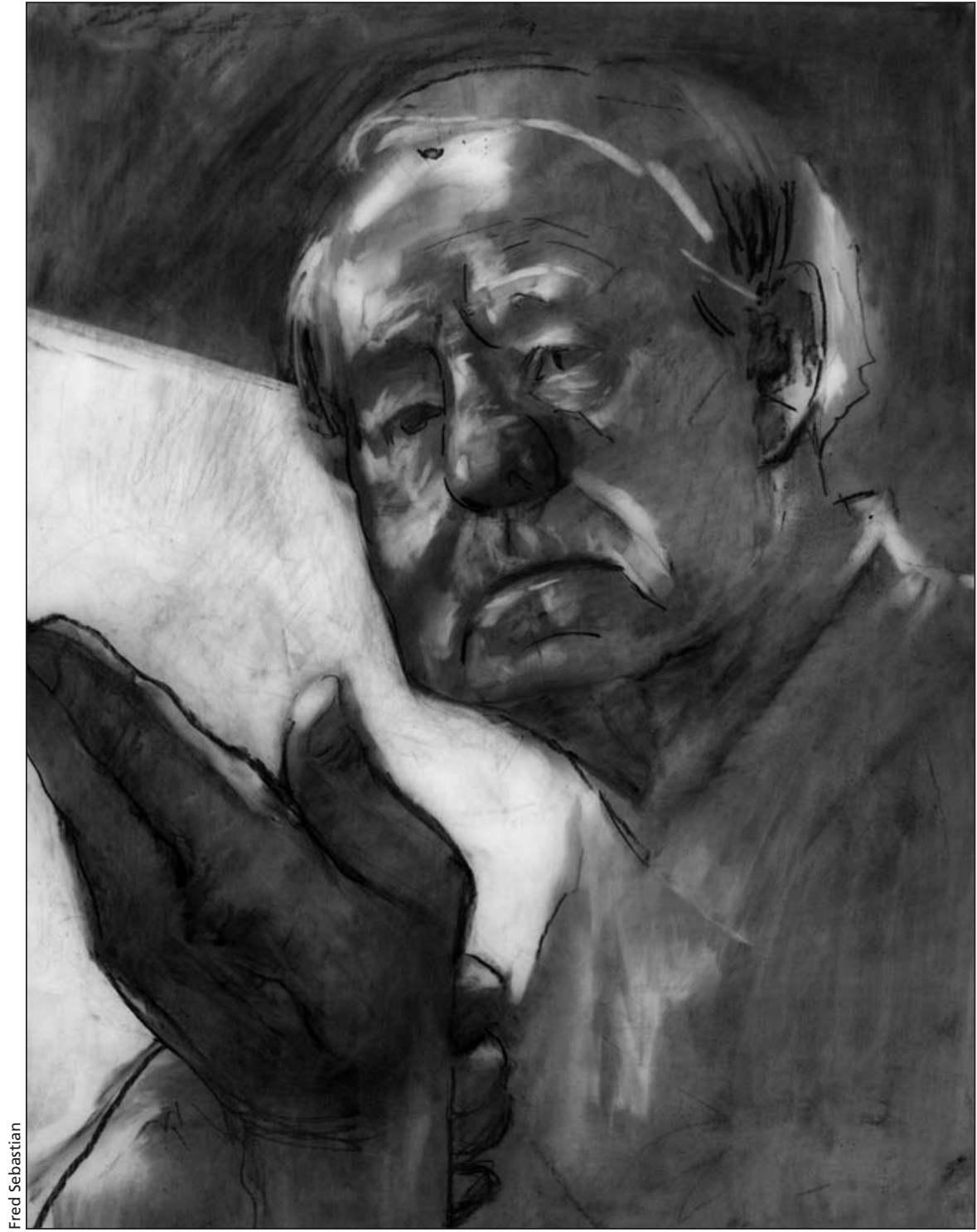

little boy whose broken neck gave way under the weight of his head, spilling a mouthful of blood onto my shoes?"

So much resentment. So much grief. A litany of examples. I listened.

"That's not what I signed up for," he whispered, pressing his hands to his temples, as if to prevent his head from bursting.

"Can anyone understand the dryness of my mouth the first time I had to tell someone their husband had died? Can someone ever be as nauseous as I am every time I hear the music that played in that child's room the evening he died? Can anybody understand what it means to be unable to erase the skeletal face of the boy I watched take two agonizing weeks to die after we stopped his fluids? And what would that mother say, serene in her gift of vision, if she saw how corneas are 
actually harvested? Shame on me for jumping on the learning experience!"

I didn't tell him, but he was sharing. Finally, after years of amassing pain, he was sharing; paving the way to his own recovery.

Medicine provides a privileged glimpse into the most tragic hours of humanity. Quietly, stealthily, we accumulate hundreds of lives' worth of sorrow into our own; seeing, hearing, smelling and feeling death like no other. Indeed, no one can understand or experience death like we do.

Perhaps, it is the pound of flesh we owe for the privilege of sharing a father's joy as he cuts his newborn's umbilical cord.

Perhaps it is the price of the tearful gratitude of the mother whose child you resuscitated.

Perhaps it is what we must bear in exchange for the satisfaction of having relieved an old man's pain.
Vicariously, we suffer. But perhaps, just perhaps, it is what distinguishes the healers, from the doctors.

\section{Steven Bellemare MD}

Child abuse pediatrician

Ottawa, Ont.

The author confirms that all patients in this work are fictitious.

CMAJ 2011. DOI:10.1503/cmaj.110204

\title{
No unifying theories but lots of chat
}

\author{
The Ethics of Consent: Theory and Practice \\ Franklin G. Miller, Alan Wertheimer, \\ Editors \\ Oxford University Press; 2009.
}

$\mathrm{A}$ reviewer should consider a book for what it is, rather than for what he might have wished it to be. And so a clinician reviewing a text on a subject of practical importance, such as consent, must take care not to expect a helpful manual for extricating oneself from thorny clinical brambles.

With that in mind, The Ethics of Consent, edited by National Institutes of Health bioethicists Franklin Miller and Alan Wertheimer, should be read as a philosophy book, with a particular philosophical goal. Having noted that issues of consent arise around sex in the bedroom, government in the state, and everywhere in between, the editors also observe a "regrettable lack of cross-fertilization among the different contexts." Consequently, they hope their book will "stimulate ... hybrid vigour" in the discussion of consent in its various guises.

Unfortunately, The Ethics of Consent fails to achieve its own purpose.

None of the contributing authors go so far as to claim to have developed a unified theory of consent. But stating that "... a theory of informed consent should be rooted in a theory that is adequate for the full range of consent contexts" suggests that one at least believes that such a theory is possible. However, there is little progress toward such a theory here.

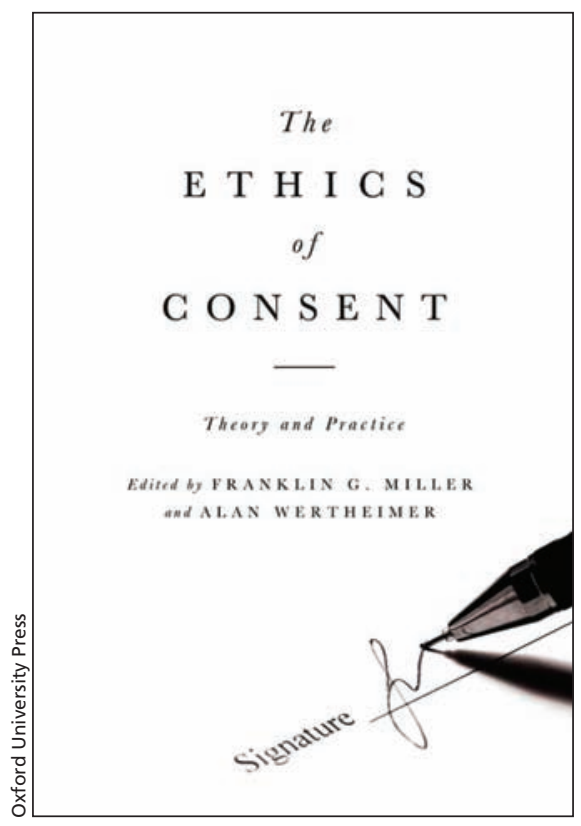

A comprehensive array of topics is covered, but presented as clearly separated subjects. This seems a peculiar decision by the editors, who lament the existing literature's lack of inter-contextual cross-talk but choose to organize their book in a way that does not engender a solution to this problem. In addition, many individual subjects are treated quite narrowly. A discussion of the legal aspects of consent to sex, for example, is largely a rebuttal of specific "liberal," "feminist," and "queer" theories. Likewise, in considering consent to medical treatment, physicians' fiduciary roles are discussed at length, but other issues, such as consent by proxies and surrogates, are mentioned only incidentally. As a sampler, rather than a survey, this book seems unlikely to create vigorous hybrid philosophies.

But it is possible that even a broader treatment would be doomed to fail. Although the term "consent" is used in a variety of contexts, the specific meaning varies widely. Is the consent that is given to a business contract or a sexual liaison substantially similar to the consent that is given to a medical treatment? The word is the same, but nearly everything else differs in important respects. Is it reasonable to expect these very different situations to have anything informative to say about one another? The ease with which the authors are able to use a standard philosopher's technique - providing counter-examples to an existing theoretic framework's reach in order to justify the construction of a new framework - suggests that an all-encompassing theory does not exist. How could any theory survive such an assault of expert and facile contradiction, especially when the underlying subject matter seems not to have any particular unity?

The Ethics of Consent does contain some interesting individual discussions, and can be usefully read as a collection of loosely connected essays. But it is not the book it wishes to be.

\section{Paul Moorehead MD}

PhD student

Pathology and Molecular Medicine

Queen's University

Kingston, Ont.

CMAJ 2011. DOI:10.1503/cmaj.110420 